just before endoscopy and after ocular testing for sensitivity. The sensitivity test was carried out in this patient with aprotinin eye drops at three strengths $(5,10$, and $50 \mathrm{KIU} / \mathrm{ml})$ at five minute intervals. He showed no evidence of acute conjunctivitis, thereby suggesting no allergy.

Despite the negative sensitivity test, when aprotinin was administered intravenously he developed a profound anaphylactic reaction with an unrecordable pulse rate and blood pressure. Active resuscitation by ventilation, massive fluid transfusion, and intravenous steroids was successful. After observation for 24 hours in the intensive care unit he was transferred to a surgical ward and discharged the next day.

\section{Discussion}

In our experience, injection of the pancreatic duct in patients undergoing endoscopic retrograde cholangiopancreatography is associated with hyperamylasaemia in $70 \%$ and acute pancreatitis in $21 \%$ of patients, patients with a history of pancreatitis being at particular risk. We therefore routinely intravenously administer the protease inhibitor aprotinin, in a bolus dose of $500000 \mathrm{KIU}$, as prophylaxis immediately before the procedure. No reports have been published detailing the method and value of ocular pretesting for aprotinin sensitivity, but it is recommended by the manufacturer of the drug (Bayer UK). Similar testing has been used for contrast media in radiology ${ }^{2}$ with varying support. ${ }^{3}$

This case highlights the fact that, although the ocular sensitivity test may correlate well for mild allergic reactions, it may not predict severe anaphylactic reactions or sudden death after the administration of aprotinin to a susceptible patient. This fact must raise doubts about the efficacy of such sensitivity testing before using aprotinin. This case also indicates that prophylactic treatment with aprotinin should be avoided in patients who have received the drug in the past, as sensitisation may not be detected by conventional testing.

\section{References}

1 Bailey AJM, ed. Data sheet compendium. London: Datapharm Publications, 1984:135.

2 Archer VW, Harris ID. An ocular test for sensitivity to Diodrast prior to intravenous urography. American fournal of Roentgenology and Radium Therapy 1942;48: 763-5.

3 Fischer $\mathrm{HW}$, Doust VL. An evaluation of pretesting in the problem of serious and fatal reactions to excretory urography. Radiology 1972;103:497-501.

(Accepted 14 August 1984)

\title{
Intravenous gammaglobulin treatment in patients with hypogammaglobulinaemia
}

\author{
A SO, M K BRENNER, I D HILL, G L ASHERSON, A D B WEBSTER
}

\begin{abstract}
Intravenous gammaglobulin was compared with the standard British intramuscular preparation in patients with hypogammaglobulinaemia and chronic bronchitis. Five patients were given six months' treatment with the weekly intramuscular preparation and six months' treatment with intravenous gammaglobulin given once every 18 days. During the trial they recorded symptoms of infection, absence from work, and sputum volume; lung function tests were performed during the intravenous treatment. The half life of the intravenous IgG and changes in serum IgG and Clq concentrations were also measured in seven other patients who received intravenous gammaglobulin every two weeks for 12 weeks. IgG concentrations, sputum volume, and infection scores were significantly better during intravenous treatment and there were no adverse effects from the intravenous gammaglobulin.

These five patients were significantly more healthy
\end{abstract} when they received an intravenous gammaglobulin

Clinical Research Centre, Harrow, Middlesex HA1 3UJ

A SO, MRCP, registrar, division of immunology and rheumatology

$M$ K BRENNER, MRCP, PHD, senior registrar and research fellow

I D HILL, DSC, member of scientific staff, division of computing and statistics

G L ASHERSON, DM, FRCP, head, division of immunological medicine

A D B WEBSTER, FRCP, consultant physician and senior scientist, division of immunological medicine

Correspondence to: Dr A D B Webster. preparation, probably because the intravenous preparation increased serum IgG concentrations. Although longer studies are needed, intravenous gammaglobulin should be considered for patients with severe chest disease and those who cannot tolerate intramuscular injections.

\section{Introduction}

It has been standard practice in England to give patients with symptomatic hypogammaglobulinaemia weekly intramuscular injections of gammaglobulin, which are painful and sometimes cause anaphylactic type reactions. ${ }^{1}$ We report a small comparative trial between the standard British intramuscular preparation and an intravenous gammaglobulin.

\section{Patients and methods}

We studied five patients with primary hypogammaglobulinaemia (serum immunoglobulin concentrations: IgG $<2, \operatorname{IgA}<0 \cdot 1$, and IgM $<0.1 \mathrm{~g} / \mathrm{l})$ and chronic bronchitis who had been receiving weekly intramuscular injections of gammaglobulin for many years. Each patient entered the trial for 12 months and received a total of six months' treatment with intravenous gammaglobulin (Immunoglobulin SRK, Sandoglobulin) ${ }^{2}$ and six months' treatment with intramuscular gammaglobulin (Blood Products Laboratory, England). To control for seasonal variation in infection rates we gave each regimen for an equal amount of time in the winter (from October to March). The intravenous gammaglobulin was given in a dose of $200 \mathrm{mg} / \mathrm{kg}$ body weight once every 18 days and the intramuscular gammaglobulin in a dose of $25 \mathrm{mg} / \mathrm{kg}$ once a week.

Patients kept daily records of symptoms of infection and absences from work, and recorded their sputum volume on either Saturday or 
Sunday in each week. Lung function tests were performed before and after the second period of intravenous treatment.

Seven further patients with hypogammaglobulinaemia (serum IgG concentrations $<2 \mathrm{~g} / \mathrm{l}$ ) were given intravenous gammaglobulin every two weeks for 12 weeks, during which the half life of the intravenous IgG and changes in serum $\mathrm{Clq}$ and $\mathrm{IgG}$ concentrations were measured.

Serum immunoglobulins were measured by laser nephelometry and the Clq by a Mancini technique, the latter being expressed as a percentage of pooled normal sera. The half life of the intravenous IgG was measured by the fall in antibodies to tetanus toxoid.

Volumes of sputum were compared using standard analysis of variance (after a logarithmic transformation) and serum IgG concentrations using paired $t$ test techniques. The figures reported for infections and time off work were not normally distributed and so were tested with a randomisation technique that is valid irrespective of the distribution of the values. This simulates the trial many times using the real data but assigns the four values for each patient at random, two to each treatment. The distribution of results that would have been observed if the allocation had been due solely to chance can then be used in assessing the actual result. ${ }^{3}$

\section{Results}

None of the 12 patients experienced reactions during or after the intravenous gammaglobulin infusions. For the five patients in the comparative trial the results for IgG concentrations, sputum volume, and infection scores were all significantly better, those for IgG concentrations highly so, during intravenous treatment than during intramuscular treatment (see table). The scores for time off work showed no significant difference.

Results of intramuscular (IM) compared with intravenous (IV) administration of gammaglobulin to five patients with hypogammaglobulinaemia

\begin{tabular}{|c|c|c|c|c|c|c|c|c|}
\hline \multirow[b]{2}{*}{ Case No } & \multicolumn{2}{|c|}{$\underset{(g / 1)^{*}}{\operatorname{Serum}} I^{*}$} & \multicolumn{2}{|c|}{$\underset{(\mathrm{ml} / \text { day }) \dagger}{\text { Sputume }}$} & \multicolumn{2}{|c|}{$\begin{array}{c}\text { Infection } \\
\text { (days/week) }\end{array}$} & \multicolumn{2}{|c|}{$\begin{array}{c}\text { Off work } \\
\text { (days/week) } \dagger\end{array}$} \\
\hline & IM & IV & IM & IV & IM & IV & IM & IV \\
\hline 1 & $1.9 \ddagger$ & $4 \cdot 2$ & \multirow{5}{*}{$\begin{array}{r}28.9 \\
74.3 \\
51.1 \\
53.6 \\
56.0 \\
22.0 \\
4.4 \\
3.7 \\
43.6 \\
29.3\end{array}$} & \multirow{5}{*}{$\begin{array}{r}26.3 \\
17.5 \\
99.8 \\
59.5 \\
22.0 \\
12.0 \\
2.2 \\
5.0 \\
33.5 \\
29.5\end{array}$} & \multirow{5}{*}{$\begin{array}{l}3.8 \\
7.0 \\
1.3 \\
2.9 \\
5.8 \\
7.0 \\
6.5 \\
5.6 \\
7.0 \\
7.0\end{array}$} & \multirow{5}{*}{$\begin{array}{l}2.9 \\
0.1 \\
2.1 \\
1.4 \\
4.7 \\
0.1 \\
7.0 \\
6.6 \\
7.0 \\
5.2\end{array}$} & \multirow{5}{*}{$\begin{array}{l}0.4 \\
1.8 \\
0.5 \\
1.6 \\
0.9 \\
0.1 \\
0.1 \\
0.1 \\
0.12 \\
0.1\end{array}$} & \multirow{5}{*}{$\begin{array}{l}1.4 \\
0.6 \\
0.1 \\
0.2 \\
0.1 \\
0.1 \\
0.1 \\
0.1 \\
0.1 \\
0.1\end{array}$} \\
\hline 2 & 2.5 & $4 \cdot 8$ & & & & & & \\
\hline 3 & $5 \cdot 3 t$ & 8.4 & & & & & & \\
\hline 4 & 3.7 & $7 \cdot 3$ & & & & & & \\
\hline 5 & $2 \cdot 0$ & $4 \cdot 0$ & & & & & & \\
\hline & & & & & & $04 \S$ & & $6 \S$ \\
\hline
\end{tabular}

* Measured at end of three month course of treatment.

+ Mean data for two three month courses of treatment.

$\$$ Supplemented with two units of fresh fro

There were no significant changes in forced expiratory volume or forced vital capacity after three months of intravenous treatment.

Both the serum IgG concentration (mean rise $2.3 \mathrm{~g} / \mathrm{l}$, range $1 \cdot 6-3.2 \mathrm{~g} / \mathrm{l}$ ) and Clq concentration (rise $34 \%$, range $5-80 \%$ ) rose after treatment in six of the seven patients given fortnightly infusions of intravenous gammaglobulin. The exception was one patient who had a short half life for IgG. The concentrations of antitetanus toxoid antibodies changed rapidly during the first $\mathbf{4 8}$ hours after infusion of $6 \mathrm{~g}$ of intravenous gammaglobulin in these seven patients, probably because antibody was redistributed into the extravascular space. Once equilibrium had been established the half life of antibody in all but one patient was longer than two weeks.

\section{Discussion}

The health of five patients improved significantly when they received an intravenous gammaglobulin preparation every 18 days compared with weekly intramuscular gammaglobulin injections, probably because the intravenous regimen significantly increased the serum IgG concentrations. The design of the trial was not ideal, and the three monthly treatment periods were too short to be sure that any possible carryover effect was avoided. More definitive studies would require at least a two $\bar{z}$ year trial with each treatment lasting for about six months.

The most common organism causing infection in patients deficient in antibodies is non-typable Haemophilus influenzae. $\widehat{\widehat{\Omega}}$ Non-capsulated $H$ influenzae will spontaneously bind $\mathrm{Clq}^{4}{ }^{4}$ and $\overline{\bar{J}}$ this may enhance opsonisation by activating the complement pathway. It is doubtful, however, whether patients with hypo- o gammaglobulinaemia have $\mathrm{Clq}$ concentrations low enough to 0 affect their predisposition to infection. Specific IgG antibody in the intravenous gammaglobulin used will opsonise $H$ influenzae $\overrightarrow{\vec{D}}$ direct, and this is not greatly enhanced by additional comple- $\overrightarrow{0}$ ment activation. ${ }^{5}$

Suitable intravenous gammaglobulin preparations should be $\overline{\bar{\omega}}$ considered for patients with severe chest disease or the few $\frac{\mathbb{D}}{\circ}$ patients who cannot tolerate the intramuscular injections because of pain or repeated reactions. Preparations with a half life of more than two weeks that contain opsonising antibodies to $H \vec{\circ}$ influenzae are preferable. Fresh frozen plasma is a possible alter- $\overrightarrow{\vec{H}}$ native, and the relative risks of transmitting hepatitis viruses by $\omega_{\mathscr{O}}$ "small pool" plasma compared with "large pool" intravenous gammaglobulin can be ascertained only when intravenous treatment has been more extensively used.

\section{References}

1 Asherson GL, Webster ADB. Diagnosis and treatment of immunodeficiency diseases. V Oxford: Blackwell Publications, 1980:7-60.

2 Barandan S, Morell A, Skvaril F. Clinical experiences with immunoglobulin for intravenous use. In: Immunoglobulins: characteristics and uses of intravenous preparations. London: HMSO, 1979:31-5. (DHSS Publication No (FDA)-809005.

3 Fisher RA. Design experiments. Edinburgh: Oliver and Boyd, 1935: section 21. 4 Prellner K. Bacteria associated with acute otitis media have high Clq binding capacity. Acta Pathol Microbiol Scand 1980:88c:187-90.

5 Lever AML, Gross J, Webster ADB. The serum factors required to opsonise non-typable H Influenzae. $\mathcal{J}$ Clin Microbiol (in press).

(Accepted 8 August 1984)

\section{ONE HUNDRED YEARS AGO}

Dr. Zulinsky has recently published, in a Polish medical paper, the result of a large series of experiments on men and animals made for the purpose of ascertaining the physiological action of tobacco-smoke on animals. He has found that the smoke is a powerful poison, even in very small quantities. In the case of man, tobacco-smoke, when not inhaled too freely, is only deleterious to a limited extent. Zulinsky declares that the poisonous character of the smoke is not entirely due $\delta$ to the nicotine which it contains. Tobacco-smoke rendered free from 3 nicotine remains poisonous, though not to so great a degree as before. The second poisonous principle is an alkaloid, colidin. Carbonic oxide, hydrocyanic acid, and other noxious principles, are also con-

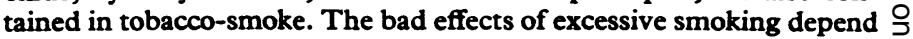
very much both on the kind of tobacco consumed, and on the manner $N$

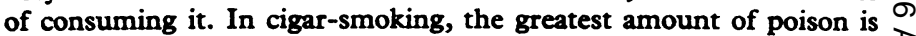
inhaled, in cigarettes much less, in pipes still less, whilst those who indulge in the nargileh, or any similar luxury, where the smoke is drawn through water, take tobacco in its least mischievous form. Such $\mathbb{O}$ are Zulinsky's conclusions. There can be little doubt that many of the light-coloured tobaccos have been partially bleached in order to $\sigma$ give them that pale tint which moderate smokers believe to be an infallible indication of mildness. The decolorising agent is suspected to be, in many cases, a deleterious chemical compound. Some of the light tobaccos smoke exceedingly hot, owing to the quantity of woody fibre which they contain. This is especially the case with "bird'seye," which is cut near the stalk of the leaf, the slices of the midrib, thick in this part of the leaf, giving this variety of tobacco the characteristic appearance from whence it derives its name. "Bird's-eye" is very apt to cause slight inflammation of the tongue, on account of the irritant character and heat of its smoke; and, together with other light tobaccos, must act very prejudicially in elderly smokers, who may be prone to cancer of the tongue or lip. Dark tobaccos are readily adulterated; but when pure they are probably the most wholesome for pipe-smoking. (British Medical Fournal 1884 ;ii :824.)

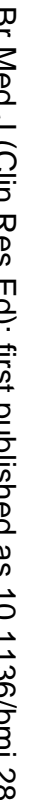

